\title{
Pulmonary hypertension in high-altitude chronic hypoxia: response to nifedipine
}

\author{
A.M. Antezana*, G. Antezana+, O. Aparicio+, I. Noriega+, F.L. Velarde*, J-P. Richalet*
}

Pulmonary hypertension in high-altitude chronic hypoxia: response to nifedipine. A.M. Antezana, G. Antezana, O. Aparicio, I. Noriega, F.L. Velarde, J-P. Richalet. OERS Journals Ltd 1998.

ABSTRACT: Permanent residents at high altitude may develop excessive polycythaemia $(\mathrm{H}-\mathrm{Hb})$ and pulmonary hypertension, which often leads to cardiac failure. Inhibitors of calcium channels have been shown to reverse pulmonary hypertension in respiratory diseases and in primary pulmonary hypertension, but their efficiency has not been evaluated in high-altitude-induced pulmonary hypertension.

Systolic pulmonary arterial pressure $\left(P_{\text {pa }}\right)$ was studied by Doppler echocardiography, at rest and after sublingual nifedipine, in 31 asymptomatic residents at $3,600 \mathrm{~m}$. Individuals were separated into two groups according to resting $P$ pa: a group with low $P$ pa (ð4.7 kPa, $n=17)$ and a group with high $P$ pa $(>4.7 \mathrm{kPa}, \mathrm{n}=14)$. Individuals were also split into two groups according to haemoglobin $(\mathrm{Hb})$ concentration: a normocy-thaemic (L-Hb) group ([Hb] $\left.\delta 180 \mathrm{~g} \cdot \mathrm{L}^{-1}, \mathbf{n}=17\right)$ and a $\mathrm{H}-\mathrm{Hb}$ group $\left([\mathrm{Hb}]>180 \mathrm{~g} \cdot \mathrm{L}^{-1}, \mathbf{n}=14\right)$.

No significant difference in $P$ pa was observed between the $\mathrm{L}-\mathrm{Hb}$ and $\mathrm{H}-\mathrm{Hb}$ groups. There was no correlation between $[\mathrm{Hb}]$ and $P$ pa. Nifedipine induced a decrease of $>20 \%$ in $P$ pa in two-thirds of the subjects. This response was correlated with higher levels of basal $P$ pa $(p<0.001)$ and was inversely correlated with age in the $\mathrm{L}-\mathrm{Hb}$ group $(\mathrm{p}<0.05)$. Pulmonary vasoreactivity to nifedipine was independent of the degree of $\mathrm{H}-\mathrm{Hb}$.

Pulmonary hypertension secondary to chronic altitude hypoxia may be reversible, despite a possible remodelling of the pulmonary arterioles. Eur Respir J 1998; 12: 1181-1185.

The vasoconstrictive effect of hypoxia upon pulmonary artery vessels is well known in most mammalian species, including humans. A pure form of hypoxic pulmonary artery hypertension can be seen in high-altitude residents. A loss of adaptation to chronic hypoxia, known as chronic mountain sickness (CMS), is observed in $5-10 \%$ of people sojourning above $3,000 \mathrm{~m}$ and is characterized by excessive polycythaemia $(\mathrm{H}-\mathrm{Hb})$, pulmonary hypertension and nonspecific neurological symptoms [1]. Ongoing pulmonary vasoconstriction leads to increased vascular resistance and pulmonary artery pressure $(P \mathrm{pa})$, which are probable maladaptive responses to high altitude since they result in minimal improvement in ventilation-perfusion matching and increased workload for the right ventricle.

In addition to vasoconstriction, chronic alveolar hypoxia is associated with structural changes in the media of terminal portions of pulmonary arterioles [2], such as smooth muscle cell proliferation, thickening of the media, proliferation and turgescence of endothelial cells. Recently, this vascular remodelling has been found in only a few residents at high altitude [3], but it is admitted that sustained hypoxia is able to increase muscularization of the small pulmonary vessels and to increase even further the pulmonary vascular resistance.

A reduction in $P$ pa, under hypoxic conditions, has been obtained by the calcium channel-blocker nifedipine in healthy humans exposed to acute normobaric hypoxia [4] or in subjects suffering from high-altitude pulmonary oedema
*Faculty of Medicine, ARPE, Biology, France. +Instituto Boliviano de Biologia de Altura, La Paz, Bolivia.

Correspondence: A.M. Antezana ARPE

Laboratoire "Réponses cellulaires et

fonctionnelles à l'hypoxie"

Faculté de Médecine

74 rue Marcel Cachin

93017 Bobigny Cedex

France

Fax: 33148387777

Keywords: Calcium channel-blockers high altitude

pulmonary hypertension

Received: March 111997

Accepted after revision July 51998

Part of a scientific programme developed between the Association pour la Recherche en Physiologie de l'Environnement and the Cardiology Department of the Instituto Boliviano de Biologia de Altura. in hypobaric hypoxia [5]. In other aetiologies of pulmonary hypertension, such as primary pulmonary hypertension [6] or secondary to obstructive pulmonary disease [7, 8], nifedipine and felodipine were efficient in decreasing $P$ pa. Calcium antagonists have also been shown to be efficient in experimental hypoxic pulmonary vasoconstriction $[9,10]$.

Reversal of hypoxic pulmonary hypertension with calcium channel-blockers has not been evaluated in a population chronically exposed to high altitude. Venesection has been used to treat CMS, but no modification of pulmonary haemodynamics has been reported.

The objectives of this study were to assess pulmonary hypertension in native residents at high-altitude by echocardiography, to analyse the relationship between $P$ pa and $\mathrm{H}-\mathrm{Hb}$, and to study the effect of acute administration of nifedipine on pulmonary pressure. In the presence of reversible vascular changes in altitude-induced pulmonary hypertension, a nifedipine-induced vasodilatation could be anticipated.

\section{Materials and methods}

Subjects

Thirty males and one females, native residents of $\mathrm{La}$ Paz $(3,500-4,100 \mathrm{~m})$, Bolivia, were included in this nonrandomized study. Asymptomatic subjects were recruited 
in the police department, whereas $\mathrm{H}-\mathrm{Hb}$ patients were followed for a family history of $\mathrm{H}-\mathrm{Hb}$ at the Instituto Boliviano de Biologia de Altura (IBBA) in La Paz. All subjects were volunteers and provided informed consent before inclusion. This study was approved by the Ethics Committee of the University Mayor de San Andrés and the IBBA. All subjects were workers or students, aged 17-55 yrs $(34 \pm 11$, mean \pm SD) and were of mixed Indian and Spanish origins. All patients underwent functional evaluation before inclusion: physical examination, chest radiography, electrocardiography, echocardiography, transcutaneous oximetry and determination of haemoglobin $(\mathrm{Hb})$ concentration. The exclusion criteria were any history of lung, cardiac or renal disease, allergies or drug consumption.

\section{Study design}

Subjects were included in various groups according to the value of their $[\mathrm{Hb}]$ and $P$ pa. The acute effect of oral nifedipine on pulmonary circulation was evaluated by Doppler echocardiography.

\section{Methods}

The normal value of $[\mathrm{Hb}]$ at $3,600 \mathrm{~m}$ is $160 \pm 20 \mathrm{~g} \cdot \mathrm{L}^{-1}$ [11]. Subjects were included in the normocythaemic (L$\mathrm{Hb})$ group when $[\mathrm{Hb}]$ was $\partial 180 \mathrm{~g} \cdot \mathrm{L}^{-1}$, and in the $\mathrm{H}-\mathrm{Hb}$ group when $[\mathrm{Hb}]$ was $>180 \mathrm{~g} \cdot \mathrm{L}^{-1}$.

Systolic $P$ pa was assessed by continuous Doppler $(3 \mathrm{MHz}$ probe, Advanced Technology Laboratory, Bothell, WA, USA), using Bernoulli's formula on tricuspidian regurgitation in a four-chamber view [12] and right atrial pressure was estimated as $1.3 \mathrm{kPa}$. Normal $P$ pa at this altitude is $4.3 \pm 0.40 \mathrm{kPa}$ [13]. Patients were included in a low $P$ pa group (LPpa) when $P$ pa was $\partial 4.7 \mathrm{kPa}$, and in a high $P$ pa group $(\mathrm{H} P$ pa $)$ when $P$ pa was $>4.7 \mathrm{kPa}$.

Right ventricle wall thickness, septal motion, left ventricle diameters and regional contractility were measured in $t \mathrm{~m}$ (time motion) mode in a longitudinal parasternal axis and in a four-chamber view. Cardiac output was calculated by an indirect method using left ventricular volumes [14]. Systemic arterial pressure was measured using a sphygmomanometer.

Clinical symptoms and signs usually described in CMS were examined, i.e. cutaneous erythaema, cyanosis, dyspnoea, headache, chest pain, finger paresthaesia, intellectual fatigue, dizziness, inappetence, myalgia and atypical arthralgias. The determination of clinical cyanosis was blinded with regard to $\mathrm{Hb}$ levels. A CMS score based on the above symptoms and signs assigns a value of 1 to negative answers, a value of 2 when symptoms are sometimes present and a value of 3 when they are frequently present [15]. The odds ratio for this score was 1.57 , the specificity was 0.91 and the negative predictive value was 0.86 . A score of 11 means that none of these complaints were present.

\section{Drug administration and criteria of efficiency}

All included subjects were scheduled to attend for a second visit for a nifedipine test. Monitoring with cardiac Doppler and a clinical survey were performed during the 2 $\mathrm{h}$ after nifedipine administration. After a 30-minute supine resting period, all patients received a first dose of 10 $\mathrm{mg}$ nifedipine sublingually. A second dose of $10 \mathrm{mg}$ nifedipine was administered when no significant variation in $P$ pa or systemic blood pressure was observed $30 \mathrm{~min}$ after the first dose. In the $\mathrm{H} P$ pa group, a third dose could be administered if $P$ pa was unchanged and if systemic blood pressure was still within normal limits. Patients were considered as responders when a reduction of $20 \%$ in $P$ pa was observed within $2 \mathrm{~h}$ after of administration [6].

\section{Statistical analysis}

Results are presented as mean \pm SD. Changes in absolute values of $P$ pa with treatment were compared using the Student's paired t-test (two-tailed). The difference between groups was considered significant when $\mathrm{p}<0.05$. Relationships between variables were tested by simple linear regression. One-way analysis of variance (ANOVA) was used for multiple comparisons.

\section{Results}

\section{Comparisons of normocythaemic and polycythaemic groups}

$\mathrm{H}-\mathrm{Hb}$ subjects were older than $\mathrm{L}-\mathrm{Hb}$ subjects $(40 \pm 10$ and $28 \pm 11$ yrs, respectively; $\mathrm{p}<0.01)$. There was a positive correlation between age and $[\mathrm{Hb}](\mathrm{p}=0.01)$ and between $[\mathrm{Hb}]$ and cardiac output $(\mathrm{p}=0.001)$. $P$ pa was not significantly different between the two groups (table 1). No relationship was found between $[\mathrm{Hb}]$ and $P$ pa. Resting cardiac frequency and blood pressure were similar, whereas cardiac output was higher in the $\mathrm{H}-\mathrm{Hb}$ group $(\mathrm{p}<0.05)$. There was a positive correlation between right ventricular diameter and cardiac output $(\mathrm{p}=0.01)$ and between right ventricular diameter and $[\mathrm{Hb}](\mathrm{p}<0.05)$.

\section{Comparisons of groups with low and high pulmonary pressure}

Age was similar in both groups $(33 \pm 11$ and $34 \pm 11$ yrs, respectively). There was no relation between age and basal $P$ pa. No relationship was found between either $P$ pa and

Table 1. - Baseline cardiovascular findings in all subjects

\begin{tabular}{lcccc}
\hline & $\mathrm{L}-\mathrm{Hb}$ & $\mathrm{H}-\mathrm{Hb}$ & $\mathrm{L} P \mathrm{pa}$ & $\mathrm{H} P \mathrm{pa}$ \\
\hline Subjects n & 14 & 17 & 17 & 14 \\
{$[\mathrm{Hb}] \mathrm{g} \cdot \mathrm{L}^{-1}$} & $173 \pm 7$ & $223 \pm 25^{*}$ & $198 \pm 25$ & $203 \pm 40$ \\
$P \mathrm{pa} \mathrm{mmHg}$ & $43 \pm 11$ & $42 \pm 14$ & $31 \pm 5$ & $51 \pm 13^{+}$ \\
$f \mathrm{C}$ beats·min & $63 \pm 11$ & $68 \pm 9$ & $67 \pm 14$ & $63 \pm 8$ \\
$\mathrm{SBP} \mathrm{mmHg}$ & $111 \pm 13$ & $121 \pm 9$ & $111 \pm 12$ & $113 \pm 13$ \\
$\mathrm{DBP} \mathrm{mmHg}$ & $79 \pm 9$ & $85 \pm 7$ & $82 \pm 8$ & $80 \pm 9$ \\
$\mathrm{Sa}_{2} \mathrm{O}_{2} \%$ & $93 \pm 2$ & $94 \pm 2$ & $94 \pm 2$ & $93 \pm 2$ \\
$A \mathrm{QRS} \circ$ & $110 \pm 20$ & $120 \pm 10$ & $110 \pm 30$ & $125 \pm 30$ \\
$\mathrm{RVd} \mathrm{mm}$ & $21 \pm 5$ & $24 \pm 4^{*}$ & $23 \pm 4$ & $23 \pm 6$ \\
$\mathrm{CO} \mathrm{L} \cdot \mathrm{min}^{-1}$ & $4.3 \pm 0.8$ & $5.3 \pm 1.2^{*}$ & $4.5 \pm 0.7$ & $4.9 \pm 1.1$ \\
\hline
\end{tabular}

Values are mean $\pm S D(n=31)$. L-Hb: normocythaemic group; $\mathrm{H}$ $\mathrm{Hb}$ : polycythaemic group; $\mathrm{L} P \mathrm{pa}$ : low pulmonary artery pressure group; $\mathrm{H} P$ pa: high pulmonary artery pressure group; $\mathrm{Hb}$ : haemoglobin; $P$ pa: systolic pulmonary artery pressure; $f \mathrm{C}$ : cardiac frequency; SBP and DBP: systolic and diastolic arterial blood pressure, respectively; $\mathrm{Sa}_{\mathrm{a}} \mathrm{O}_{2}$ : arterial oxygen saturation; $A \mathrm{QRS}$ : QRS electrical axis; RVd: right ventricular diameter; $\mathrm{CO}$ : cardiac output. *: $\mathrm{p}<0.01$ for L-Hb versus $\mathrm{H}-\mathrm{Hb}$; + p $<0.01$ for LPp versus $\mathrm{HPp}$. 
cardiac output or $P$ pa and systemic blood pressure. Cardiac frequency was similar in both groups, as were the other parameters shown in table 1.

\section{Echocardiography}

The measurement of peak velocity of tricuspid regurgitation, used for calculating $P$ pa, was performed by two observers and the correlation between the two measures was $\mathrm{r}=0.80$ and $\mathrm{sE}=10 \mathrm{~cm} \cdot \mathrm{s}^{-1}$. The right atrium was not enlarged on inspection in a four-chamber view and the largest diameter in any subject was $<40 \mathrm{~mm}$. No leftward displacement of the interventricular septum was observed. Left ventricular contractility and wall kinetics were normal in all subjects. No right-to-left shunting was evidenced with pulsed Doppler.

\section{Chronic mountain sickness symptoms}

A score of $14 \pm 2$ was found in the L-Hb group and $16 \pm 2$ in the $\mathrm{H}-\mathrm{Hb}$ group (nonsignificant). The score was correlated with $[\mathrm{Hb}](\mathrm{p}=0.02)$ and was not correlated with age. The score did not differ between $L P$ pa and $\mathrm{H} P$ pa groups: $15 \pm 3$ and $16 \pm 2$, respectively. No relationship was found between symptoms and any haemodynamic parameter. $\mathrm{L}-\mathrm{Hb}$ subjects with normal $P$ pa did not complain of exertional dyspnoea. Dyspnoea was present in eight out of 17 patients with $\mathrm{H}-\mathrm{Hb}$, mainly when $[\mathrm{Hb}]$ was $>200 \mathrm{~g} \cdot \mathrm{L}^{-1}$. Half of the patients with pulmonary hypertension described exertional dyspnoea, as did five out of the 17 subjects with $\mathrm{LP}$ pa. Cyanosis of the lips was observed in 12 out of $17 \mathrm{H}-$ $\mathrm{Hb}$, and in eight out of $14 \mathrm{~L}-\mathrm{Hb}$ subjects $(\mathrm{p}<0.05)$. Cyanosis was present in 10 out of $14 \mathrm{H} P$ pa patients and in six out of $17 \mathrm{LP}$ pa subjects. Headache was frequent in $\mathrm{H}-\mathrm{Hb}$ patients (nine out of 17), and seldom present in L-Hb subjects (three out of 14), $(\mathrm{p}<0.05)$.

\section{Pharmacological response to nifedipine}

Most of the subjects $(\mathrm{n}=21)$ received $20 \mathrm{mg}$ nifedipine. Low systemic blood pressure did not allow the dose to be increased in seven subjects. A third dose of nifedipine was given to three patients with $P$ pa $\breve{S} 5.3 \mathrm{kPa}$. Nifedipine was mostly well tolerated, with transient headache and facial flush in five individuals, without sustained arterial hypotension. The systemic response to nifedipine was similar in $\mathrm{L}-\mathrm{Hb}$ and $\mathrm{H}-\mathrm{Hb}$ groups, with significant decreases in systolic and diastolic blood pressure $(\mathrm{p}<0.001)$ and significant increases in cardiac frequency $(\mathrm{p}<0.001)$ and cardiac

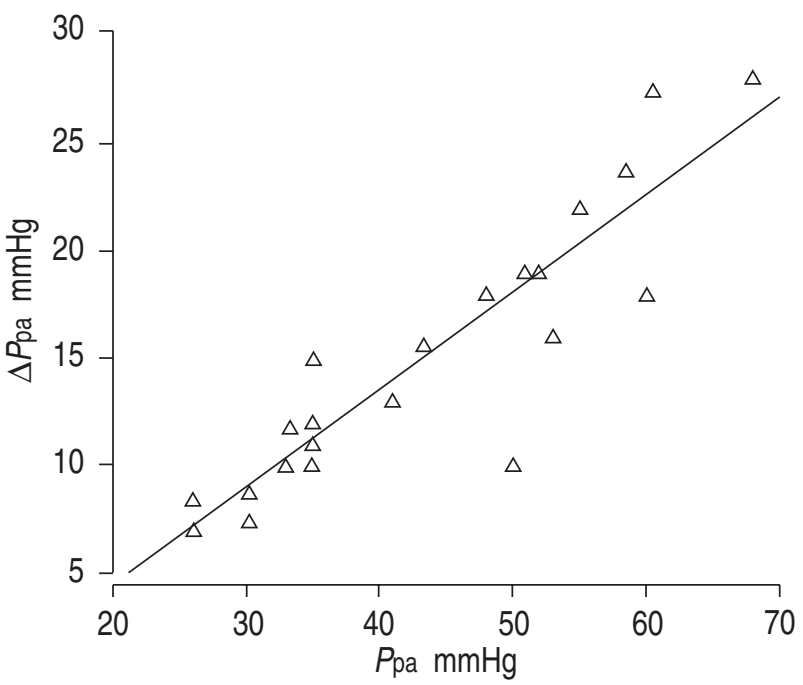

Fig. 1. - Significant correlation between basal systolic pulmonary artery pressure $(P \mathrm{pa})$ and the variation in $P$ pa induced by nifedipine treatment (ý $P$ pa), in absolute values $\left(\mathrm{y}=0.452 \mathrm{x}-4.691, \mathrm{r}^{2}=0.827\right.$, $\mathrm{p}=0.0001)$.

output $(\mathrm{p}<0.05)$. Table 2 shows the cardiovascular changes in the 23 responders to nifedipine and in the eight nonresponders. $P$ pa decreased in both the $\mathrm{L} P$ pa and $\mathrm{H} P$ pa groups $(\mathrm{p}<0.05)$. This reduction correlated with the basal values of $P$ pa (fig. 1) but not with the variation in systolic or diastolic blood pressure, cardiac output or cardiac frequency. The reduction in $P$ pa was inversely correlated with age in the $\mathrm{L}-\mathrm{Hb}$ group $(\mathrm{r}=0.6, \mathrm{p}<0.05)$. The nifedipine-induced increase in cardiac output and decrease in diastolic blood pressure were greater in the $\mathrm{L} P$ pa than the $\mathrm{H} P$ pa group $(\mathrm{p}<$ $0.05)$.

The only female included (18 yrs old) showed mild $\mathrm{H}$ $\mathrm{Hb}$ and mild pulmonary hypertension and responded to nifedipine.

\section{Nonresponders.}

$P$ pa did not change in eight subjects, after $20 \mathrm{mg}$ nifedipine in five of them and after $30 \mathrm{mg}$ in the other three. Six of these subjects had normal $P$ pa and the other two had a slightly higher $P$ pa. Three subjects were $\mathrm{L}-\mathrm{Hb}$ and the other five were $\mathrm{H}-\mathrm{Hb}$. Nonresponders were older $(\mathrm{p}<0.01)$ and showed higher systolic and diastolic blood pressure $(\mathrm{p}<0.01)$. A greater reduction in systolic blood pressure after nifedipine was found in these subjects (table 2).

Table 2. - Cardiocirculatory changes after nifedipine administration

\begin{tabular}{|c|c|c|c|c|c|c|c|}
\hline & $\begin{array}{c}\text { Subjects } \\
\mathrm{n}\end{array}$ & $\begin{array}{c}\text { ýP pa } \\
\mathrm{mmHg}\end{array}$ & $\begin{array}{c}\text { ýP } P_{\mathrm{pa}} \\
\%\end{array}$ & $\begin{array}{c}\text { ýfC } \\
\text { beats } \cdot \min ^{-1}\end{array}$ & $\begin{array}{c}\text { ýCO } \\
\mathrm{L} \cdot \mathrm{min}^{-1}\end{array}$ & $\begin{array}{l}\text { ýSBP } \\
\mathrm{mmHg}\end{array}$ & $\begin{array}{l}\text { ýDBP } \\
\mathrm{mmHg}\end{array}$ \\
\hline $\mathrm{L} P_{\text {pa }}$ responders & 11 & $-10 \pm 3$ & $-31 \pm 5$ & $+9 \pm 7$ & $+1.0 \pm 1.1$ & $-14 \pm 8$ & $-14 \pm 8$ \\
\hline $\mathrm{H} P$ pa responders & 12 & $-20 \pm 5^{++}$ & $-36 \pm 7$ & $+11 \pm 7$ & $+0.6 \pm 0.5^{++}$ & $-13 \pm 8$ & $-9 \pm 7++$ \\
\hline Nonresponders & 8 & $-2 \pm 2 * *$ & $-5 \pm 5 * *$ & $+9 \pm 5$ & $+0.4 \pm 0.3 *$ & $-23 \pm 9 * *$ & $-9 \pm 8$ \\
\hline
\end{tabular}

Values are mean \pm SD $(n=31)$. ý: variation in each variable in response to nifedipine administration; $P$ pa: systolic pulmonary artery pressure; $f \mathrm{C}$ : cardiac frequency; CO: cardiac output; SBP and DBP: systolic and diastolic arterial blood pressure, respectively; LP pa: low pulmonary artery pressure group; $\mathrm{H} P$ pa: high pulmonary artery pressure group. $*$ : $\mathrm{p}<0.05, * *$ : $\mathrm{p}<0.001$, for nonresponders $v e r s u s$ responders; ${ }^{++}$: $\mathrm{p}<0.001$ for $\mathrm{L} P$ pa responders versus $\mathrm{H} P$ pa responders. 


\section{Discussion}

Moderate to mild pulmonary hypertension was found in 14 out of 31 residents at high altitude in this nonrandomized study at $3,600 \mathrm{~m}$. Unexpectedly, $P$ pa did not increase with age. The lack of relationship between pulmonary hy-pertension and $\mathrm{H}-\mathrm{Hb}$ in this population is a new finding. Nifedipine was efficient in decreasing $P$ pa by $34 \%$ in two thirds of the subjects. No symptom or sign usually des-cribed in CMS correlated with pulmonary hypertension.

The low $P$ pa found in some individuals indicates a good adaptive mechanism to chronic hypoxia and minimal pulmonary vasoconstriction in healthy individuals, as observed in normal Tibetans at 3,658 $\mathrm{m}$ [16]. Various conditions were observed in this study: subjects with high levels of $P$ pa without $\mathrm{H}-\mathrm{Hb}$, and patients with excessive $\mathrm{H}-\mathrm{Hb}$ with no pulmonary hypertension. One explanation could be the inter-individual variability in pulmonary vasoreactivity, such as in normal subjects at sea level or in patients with chronic obstructive pulmonary disease.

The thresholds used for $[\mathrm{Hb}]$ and for $P$ pa may have influenced the results. In young individuals, an $[\mathrm{Hb}]$ of 170 $180 \mathrm{~g} \cdot \mathrm{L}^{-1}$ may be considered abnormal. Conversely, an iron deficit, which was not assessed here, could explain the relatively low $[\mathrm{Hb}]$ in some subjects. The threshold of $4.7 \mathrm{kPa}$ for $P$ pa was chosen according to previous invasive studies at the same altitude $[13,17]$ and according to local experience with cardiac Doppler in healthy subjects (unpublished data). However, individuals with $5.3 \mathrm{kPa} P$ pa were not very different from those with 4.7 or $4.0 \mathrm{kPa}$, but were considered as hypertensive for this altitude. The right atrial pressure was calculated as at sea level $(1.3 \mathrm{kPa})$ and this probably resulted in an underestimation of $P$ pa. The large age range may have influenced the results, but an analysis within smaller groups did not modify the results.

The reduction in $P$ pa by nifedipine in this nonrandomized study provides an argument against a fixed component of pulmonary hypertension. This response was positively correlated with basal $P$ pa and was independent of other haemodynamic parameters. Responsiveness inversely correlated with age in the L-Hb subjects. The successful re-versibility of pulmonary hypertension in some residents at high altitude brought to sea level is also consistent with the lack of irreversible intimal fibrosis [2]. A subgroup of $\mathrm{H}-\mathrm{Hb}$ subjects with high cardiac output did not show ex-cessive pulmonary hypertension; this could be explained by their ability to decrease pulmonary vascular resistance in response to large increases in pulmonary blood flow [18]. The other subgroup of $\mathrm{H}-\mathrm{Hb}$ subjects with pulmonary hypertension but low cardiac output may have elevated basal pulmonary vascular resistance, due either to anat-omical remodelling or to greater vasoconstriction. Nevertheless, these subjects responded to nifedipine, suggesting a true vasodilatation. This response was probably also secondary to a recruitment of pulmonary vessels.

Short-term correction of hypoxia by oxygen inhalation, in a similar population, showed no effects on $P$ pa at rest, but decreased the exercise-induced increment [19], suggesting the presence of pulmonary vasoconstriction during exercise and, thus, a dynamic regulation of pulmonary vascular resistance. Moreover, the fall in pulmonary vascular resistance during unilateral pulmonary occlusion de- monstrated the ability of pulmonary vessels to passively distend in chronic hypoxia [17].

A reduction in $P$ pa could limit the evolution of fixed vascular changes, as verapamil and nifedipine have been shown experimentally to inhibit the pressor response to acute intermittent hypoxia in rats and reverse the right ventricular hypertrophy and the medial thickening of pulmonary arterioles [10]. The reactivity of pulmonary vessels at high altitude might depend on the intensity of the vascular remodelling $[2,3]$, but also on the endotheliumdependent pulmonary vasodilation, which has been found to be impaired in experimental chronic hypoxia [20]. Indirect evidence of endothelial dysfunction has also been shown in humans exposed to acute hypoxia [21, 22].

The evaluation of $P$ pa in individuals residing at high altitude should be performed more systematically since the incidence of respiratory diseases in this population is elevated, and in particular, since symptoms are serious and appear late in the evolution of disease. Pulmonary vascular changes may be present regardless of $[\mathrm{Hb}]$, as shown in experimental chronic hypoxia [23, 24]. Iron deficit should also be assessed, particularly regarding pseudonormal $[\mathrm{Hb}]$. Patients with high altitude pulmonary hypertension, with or without excessive $\mathrm{H}-\mathrm{Hb}$, could benefit from a therapy using vasodilators when descent to a lower altitude is unfeasible. Calcium channel-blockers could be beneficial in this condition, but their efficacy should first be demonstrated during longer periods and should not lead to a deterioration in the ventilation-perfusion relationships or impair the hypoxic regulation of the pulmonary circulation, as observed in chronic obstructive pulmonary disease [8].

In conclusion, mild pulmonary hypertension in high-altitude residents was not linked to the degree of polycythaemia. Nifedipine was efficient in reducing pulmonary artery pressure and this effect was independent of the degree of polycythaemia. Pulmonary hypertension induced by chronic high altitude hypoxia could be partially reversible despite vascular remodelling. The prognostic implications of using vasodilators in this form of pulmonary hypertension are unknown, but the evolution towards cardiac failure could be prevented.

Acknowledgements: The authors are grateful to R. Carreon from the Hospital Obrero and to J. Araoz and H. Ugarte from the Instituto Boliviano de Biologia de Altura.

\section{References}

1. Monge MC. High altitude disease. Arch Intern Med 1937; 59: 32-40.

2. Arias-Stella J, Saldana M. The terminal portion of the pulmonary arterial tree in people native to high altitude. Circulation 1963; 28: 915-925.

3. Heath D, Williams D, Rios-Dalenz J, Calderon M, Gosney J. Small pulmonary arterial vessels of Aymara Indians from the Bolivian Andes. Histopathology 1990; 16: 565-571.

4. Naeije R, Mélot C, Mols P, Hallemans R. Effects of vasodilators on hypoxic pulmonary vasoconstriction in normal man. Chest 1982; 4: 404-410.

5. Bärtsch P, Maggiorini M, Rittert M, Noti C, Vock P, Oelz 
O. Prevention of high pulmonary oedema by nifedipine. N Engl J Med 1991; 325: 1284-1289.

6. Rich S, Brundage BH. High dose channel-blocking therapy for primary pulmonary hypertension: evidence for long term reduction in pulmonary arterial pressure and regression of right ventricular hypertrophy. Circulation 1987; 76: 135-141.

7. Simoneau G, Escourrou P, Duroux P, Lockhart A. Inhibition of hypoxic pulmonary vasoconstriction by nifedipine. N Engl J Med 1981; 304: 1582-1585.

8. Sajkov D, McEvoy RD, Cowie RJ. Felodipine improves pulmonary hemodynamics in chronic obstructive pulmonary disease. Chest 1993; 103: 1354-1361.

9. McMurtry IF, Davidson AB, Reeves JT, Grover RF. Inhibition of hypoxic pulmonary vasoconstriction by calcium antagonists in isolated rat lungs. Circ Res 1976; 38: 99104.

10. Stanbrook HS, Morris KG, McMurtry IF. Prevention and reversal of hypoxic pulmonary hypertension by calcium antagonists. Am Rev Respir Dis 1984; 130: 81-85.

11. Ergueta J, Spielvogel H, Cudkovicz L. Cardio-respiratory studies in chronic mountain sickness (Monge's syndrome). Respiration 1971; 28: 485-517.

12. Berger M, Halmowitz A, Van Tosh A, Berdoff RL, Goldberg L. Quantitative assessment of pulmonary hypertension in patients with tricuspid regurgitation using continuous wave Doppler ultrasound. J Am Coll Cardiol 1985; 6: 359-365.

13. Antezana G, Barragan L, Coudert J, et al. The pulmonary circulation of high altitude natives. In: Brendel W, Zink RA, eds. High Altitude Physiology and Medicine. New York, Springer, 1982; pp.142-149.

14. Eysmann SB, Harold IP, Reichek N, Hackney K, Douglas P. Two-dimensional and Doppler-echocardiographic and cardiac catheterization correlates of survival in primary pulmonary hypertension. Circulation 1989; 80: 353360.
15. Leon-Velarde F, Arrégui A, Vargas M, Huicho L, Acosta R. Chronic mountain sickness and the effect of chronic lower respiratory disorders. Chest 1994; 106: 151-155.

16. Groves BM, Droma T, Sutton J, et al. Minimal hypoxic pulmonary hypertension in normal Tibetans at $3658 \mathrm{~m} . J$ Appl Physiol 1993; 74: 312-318.

17. Antezana G, Paz Zamora M, Vargas E, et al. Estudio de la circulacion pulmonar a proposito de la occlusion temporal de la arteria pulmonar en sujetos normales a elevadas altitudes. In: Anuario 1971-1973. La Paz, Universidad Mayor de San Andrés, 1975; pp. 23-28.

18. Anand IS. Hypoxia and the pulmonary circulation. Tho$\operatorname{rax} 1994 ;$ 49: S19-S24.

19. Lockhart A, Zelter M, Mensch-Dechene J, et al. Pressure-flow-volume relationships in pulmonary circulation of normal highlanders. J Appl Physiol 1976; 41: 449456.

20. Adnot S, Raffenstin B, Eddahibi S, Braquet P, Chabrier PE. Loss of endothelium-dependent relaxant activity in the pulmonary circulation of rats exposed to chronic hypoxia. J Clin Invest 1991; 87: 155-162.

21. Schneider JC, Blazy I, Déchaux M, Rabier D, Mason N, Richalet JP. Response of nitric oxide pathway to Larginine infusion in high altitude hypoxia. In: Houston CS, Coates G, eds. Hypoxia. Women at Altitude. Burlington, Queen City Printers, 1997; p. 323.

22. Scherrer U, Vollenweider L, Delabays A, et al. Inhaled nitric oxide for high-altitude pulmonary oedema. $N \mathrm{Engl}$ J Med 1996; 334: 624-629.

23. Janssens SP, Thompson BT, Spence CR, Hales CA. Polycythemia and vascular remodeling in chronic hypoxic pulmonary hypertension in guinea pigs. J Appl Physiol 1991; 71: 2218-2223.

24. Rabinovitch M, Gamble WJ, Nadas AS, Miettinen OS, Reid L. Rat pulmonary circulation after chronic hypoxia: hemodynamic and structural features. Am J Physiol 1979; 236: H818-H827. 